\title{
Pra Rancangan Pabrik Pembuatan Biodiesel dari Proses Non Katalitik Transesterifikasi-Esterifikasi Palm Fatty Acid Distillate (Pfad) dengan Kapasitas Produksi 100.000 Ton/Tahun
}

\author{
Zakiyah Humairah L ${ }^{1}$, Nazarudin ${ }^{1}$, dan Edwin Permana \\ ${ }^{1}$ Program Studi Teknik Kimia, Fakultas Teknik, Universitas Jambi, Jambi, Indonesia
}

Email: zakiyahhl97@gmail.com

\section{Info Artikel}

Diterima: 8 Oktober 2019

Disetujui: 18 Januari 2020

Dipublikasikan: 28 Januari 2020

\section{Alamat Korespondensi: \\ zakiyahhl97@gmail.com \\ Copyright (c) 2020 Jurnal \\ Engineering}

This work is licensed under the Creative Commons Attribution International License (CC BY 4.0).

\begin{abstract}
Abstrak
Biodiesel adalah bahan bakar yang berasal dari minyak nabati yang dapat diperbaharui, dapat dihasilkan secara periodik, juga ramah lingkungan. Proses dalam pembuatan biodiesel Biodiesel ini yaitu dengan proses nonkatalitik transesterifikasi-esterifikasi. Biodiesel yang dihasilkan memiliki kemurnian 98,6\%. Kapasitas produksi pabrik yang direncanakan 100.000 ton/tahun dengan 300 hari kerja selama 24 jam dalam 1 tahun. Lokasi pabrik didirikan di Kecamatan Bandar, Kabupaten Simalungun, Sumatera Utara. Penyediaan kebutuhan utilitas pabrik berupa sistem pengolahan dan penyediaan air,sistem penyediaan steam, sistem penyediaan udara instrumen, dan sistem pembangkit tenaga listrik Hasil analisa ekonomi, pabrik biodiesel ini dinyatakan layak untuk didirikan, dengan rincian Annual Cash Flow (ACF) US\$ 79.559.278,9211, Rate of Return on Investment (ROI) : 27,8883\%, Rate of Return based on Discounted Cash Flow (DCF) : 20,49\%, Break Even Point (BEP) : 33,7298\%, Pay Out Time (POT) : 3 tahun. Dari hasil analisa aspek ekonomi dapat disimpulkan bahwa pabrik Pembuatan Biodiesel ini layak untuk didirikan.
\end{abstract}

Kata kunci: Biodiesel, PFAD, Non-Katalitik, TransesterifikasiEsterifikasi

\section{Pendahuluan}

Indonesia memiliki Sumber Daya Alam (SDA) yang melimpah, terutama minyak bumi dan gas alam. Namun pada kenyataannya, krisis energi tetap terjadi saat ini. Krisis energi ini disebabkan karena semakin meningkatkannya selisih antara konsumsi dan produksi dari bahan bakar minyak setiap tahunnya. Upaya pencarian energi alternatif sebagai pengganti suplai energi berbasis minyak bumi saat ini sedang dilakukan oleh berbagai pihak. Hal tersebut didorong karena kebutuhan akan minyak bumi dari berbagai sektor. Salah satu energi alternatif yang saat ini dikembangkan adalah biodiesel. Biodiesel merupakan energi alternatif pengganti solar yang digunakan sebagai bahan bakar mesin diesel. Salah satu alasan biodiesel terus 
dikembangkan yaitu bahan baku pembuatan biodiesel adalah trigliserida maupun asam lemak yang dapat diperoleh dari sekitar salah satunya dari produk samping ataupun limbah dari industri oleokimia (minyak goreng).Biodiesel dapat dibuat dari bahan baku Palm Fatty Acid Distillate (PFAD) yang merupakan produk samping ataupun limbah dari industri oleokimia (minyak goreng).

Berdasarkan data yang diperoleh dari Kementrian ESDM tahun 2019 diketahui bahwa konsumsi solar di Indonesia sangatlah tinggi. Dengan menggunakan metode regresi linier, didapatkan jumlah konsumsi solar pada tahun 2024 adalah sebesar 7.120.000.000 kilo liter, sehingga seluruh kebutuhan biodiesel di dalam negeri masih di impor dari beberapa negara.

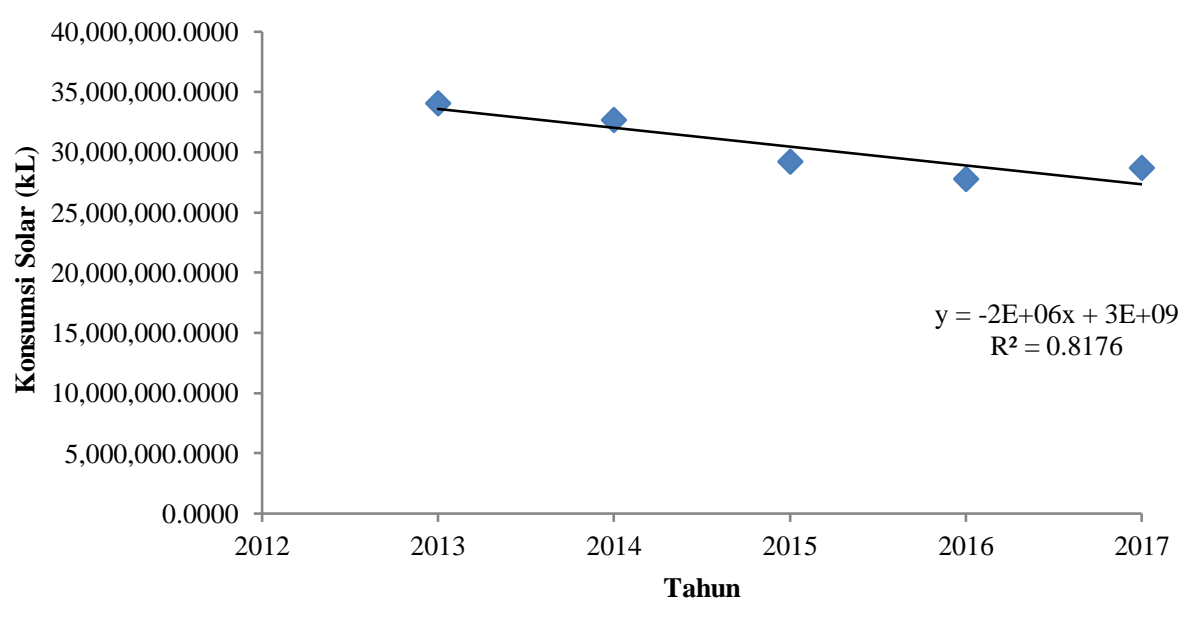

Gambar 1. Grafik Konsumsi Solar

Berdasarkan Peraturan Menteri ESDM nomor 12 tahun 2015, bahan bakar solar pada tahun 2025 harus sudah mencapai E30. Oleh karena itu, kebutuhan biodiesel pada 2025 akan meningkat, untuk memenuhi 30\% dari jumlah tersebut. 30\% dari jumlah konsumsi solar tersebut adalah 2.136.000.000 kilo liter. Jumlah tersebut dikurangi dengan pabrik yang telah memproduksi biodiesel fuel grade.

Bahan baku yang digunakan untuk pembuatan biodiesel ini adalah Palm Fatty Acid Distillate (PFAD). Ditinjau dari bahan baku berupa PFAD yang didapatkan dari hasil samping atau juga menjadi limbah dari pabrik Minyak Goreng. Pada proses pembuatan minyak goreng hasilnya berupa 73\% Olein untuk minyak goreng, 21\% Stearin, 5\% PFAD, 1\% pengotor lain (Kemenperin, 2017) Maka ketersediaan PFAD dapat diperkirakan $\left((5 / 100)^{\star}\right.$ produksi minyak goreng $\left.)\right)$.

Dengan menggunakan metode regresi linier, didapatkan ketersediaan PFAD pada tahun 2024 adalah sebesar 3.965.640 kilo liter. Dimana data tersebut dijadikan grafik yang dapat dilihat pada gambar 2. 


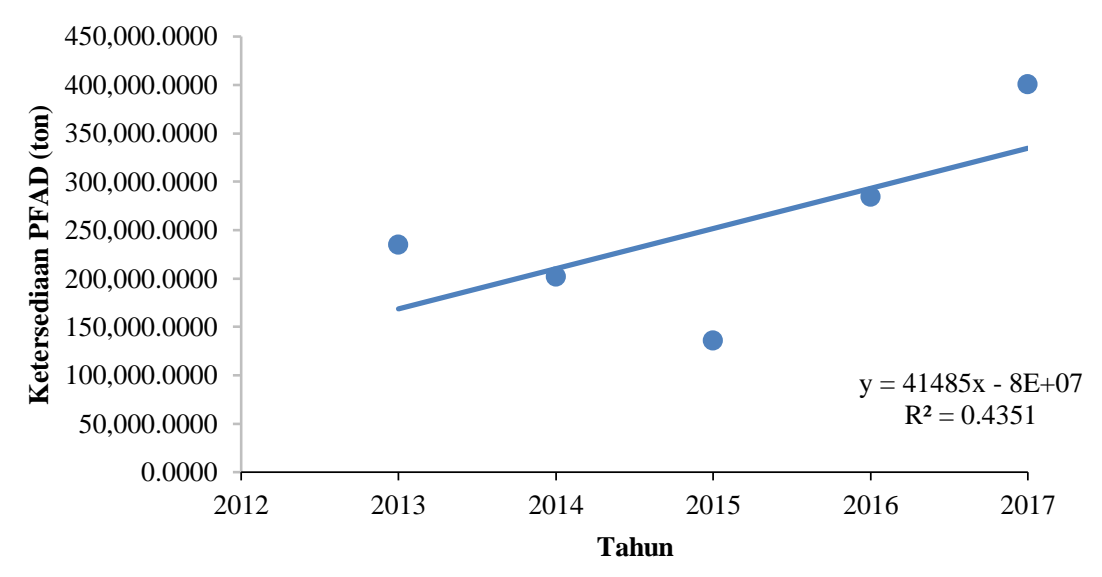

Gambar 2. Grafik Ketersedian PFAD

Diketahui bahwa Sumatera Utara merupakan daerah penghasil minyak goreng terbesar di Indonesia yaitu sebesar 30\% (Komisi Pengawas Persaingan Usaha, 2007), maka ketersedian PFAD di Sumatera Utara tahun 2024 yaitu sebesar 1.189.692. PFAD yang dibutuhkan untuk menjalankan pabrik dengan kapasitas produksi 100.000 ton/tahun ini adalah 13,45\% dari ketersedian di Sumatera Utara yaitu 160.000 ton/tahun.

\section{Deskripsi Proses}

Proses pembuatan Biodiesel berdasarkan uraian proses dari U.S Patent 2018/0346831A1 "Systems and Methods for The Non -Catalytic Production Of Biodiesel From Oils". Bahan baku berupa PFAD dan metanol pada reaktor (R-01) terjadi reaksi transesterifikasi yaitu reaksi antara metanol dan trigliserida dari PFAD dengan rasio mol 1:40 membentuk FAME (biodiesel) dan gliserol. Maka keluaran reaktor berupa FAME (biodiesel) yang merupakan produk utama, gliserol, air, unsaponifiable material, FFA dan reaktan yang tidak bereaksi (trigliserida dan metanol). Flash Drum (FD-01) bertujuan untuk memisahkan air dan metanol dari produk keluaran reaktor. Air dan metanol yang teruapkan (aliran top) kemudian menuju distilasi metanol (KD-03) dengan tujuan meningkatkan kemurnian metanol menjadi 99,8\% agar dapat di gunakan kembali pada reaktor (R-01), namun sebelumnya dicampurkan terlebih dahulu pada MP-01 dengan metanol dan air dari Flash Drum yang lain (FD-02 dan FD-03).

Bottom product dari Flash Drum (FD-01) berupa gliserol, air sisa, unsaponifiable material, FFA dan reaktan yang tidak bereaksi (trigliserida dan metanol sisa). kemudian dicampurkan dengan air (rasio berat 1 air : 1 gliserol) lalu dialirkan menuju dekanter (DK-01), penambahan air dilakukan dengan tujuan untuk memudahkan pemisahan gliserol. Pada dekanter (DK-01) terjadi pemisahan antara fase ringan (gliserol,air,metanol) dan fase berat (FAME/biodiesel, trigliserida, FFA, unsaponifiable material). Fase ringan kemudian menuju Flash Drum (FD-02) untuk dilakukan pemurnian gliserol dari air dan metanol. Kondisi operasi pada Flash Drum (FD-02). Gliserol sebagai produk samping yang dihasilkan memiliki 
kemurnian 99,3\%. Kondisi operasi penyimpanan gliserol pada suhu $30^{\circ} \mathrm{C}$ dan tekanan 1 atm pada tangki penyimpanan gliserol (T-04).

Fase berat berupa FAME (biodiesel), trigliserida, FFA, unsaponifiable material kemudian menuju distilasi (KD-02) untuk mengambil distilat berupa FAME (biodiesel) menjadi produk samping dengan kemurnian 96,3\%. FAME (biodiesel) berupa keluaran bawah (bottom) distilasi akan digunakan sebagai bahan baku Fatty Alkohol. Kondisi operasi penyimpanan FAME (biodiesel) pada suhu $30^{\circ} \mathrm{C}$ dan tekanan 1 atm sehingga sebelum menuju ke tangki penyimpanan gliserol (T-04) maka dimasukkan terlebih dahulu ke cooler (CO-04).

Sisa FAME (biodiesel), trigliserida yang tidak bereaksi, FFA dan unsaponfiable materials dari distilasi (KD-02) kemudian menuju ke reaktor esterifikasi (R-02) dengan pompa untuk menaikkan tekanan menjadi 136 atm. Di reaktor (R-02) terjadi reaksi antara metanol dan FFA dari PFAD dengan rasio mol 1:40 membentuk FAME (biodiesel) dan air. Kondisi operasi reaktor yaitu $291^{\circ} \mathrm{C}$ dan tekanan $136 \mathrm{~atm}$. Pada Flash Drum (FD-03) air dan metanol dari aliran atas menuju ke mixing point (MP-02). Aliran bawan (bottom) dari Flash Drum yiatu biodiesel, unsaponifiable materials, trigliserida, FFA dan gliserol sisa kemudian menuju kolom distilasi (KD-02) untuk memisahkan biodiesel dengan komponen lainnya.

Maka produk samping ke 2 di aliran bawah (bottom) yaitu unsaponfiable materials. Distilat dari kolom distilasi adalah biodiesel dengan kemurnian 98,6\% sebagai produk utama. Masing-masing produk disimpan didalam tangki (T-07 dan T-08) dengan kondisi operasi penyimpanan pada suhu $30^{\circ} \mathrm{C}$ dan tekanan $1 \mathrm{~atm}$.

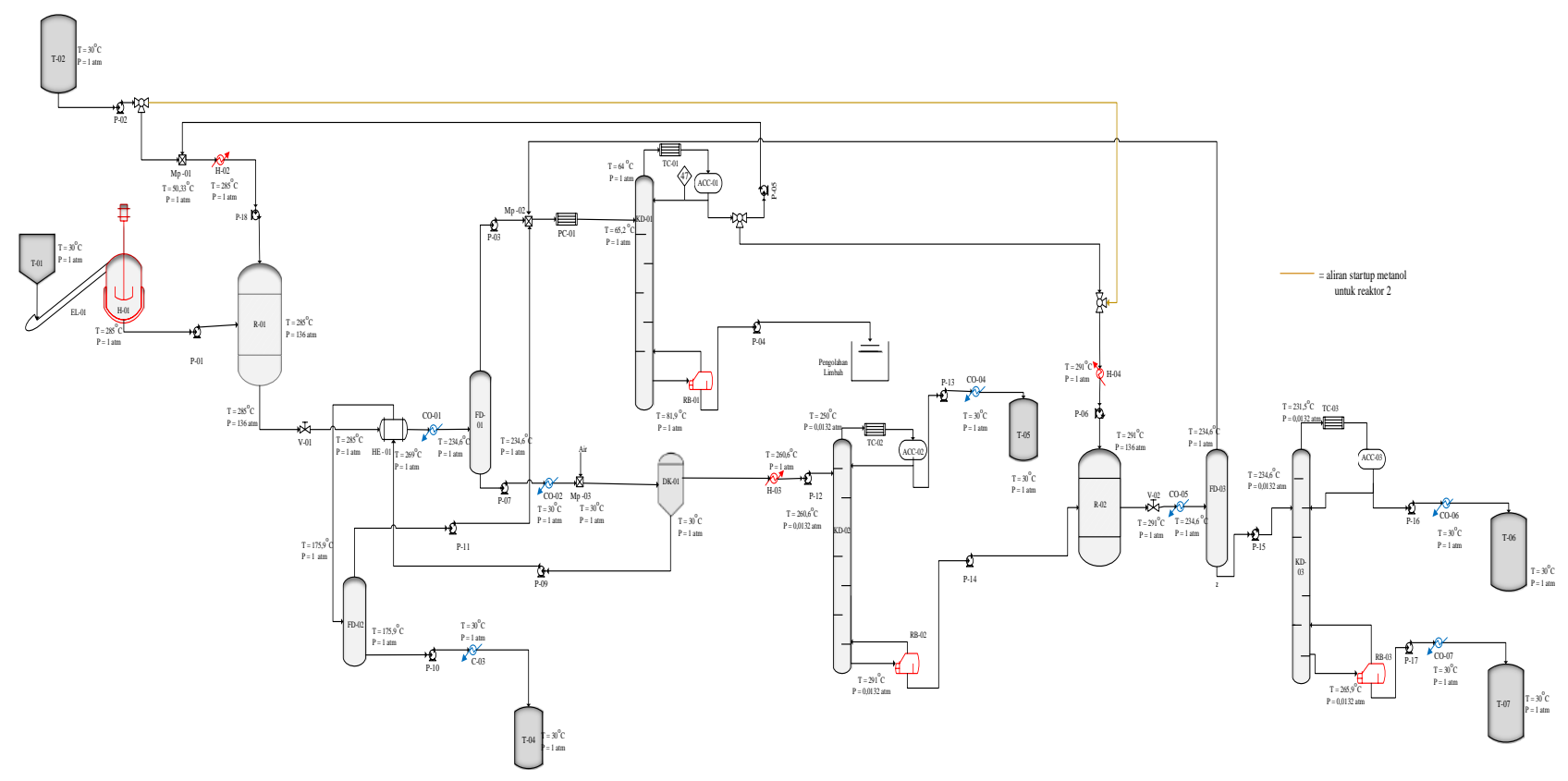

Gambar 3. Perancangan 


\section{Tata Letak Pabrik}

Pemilihan dan penentuan lokasi pabrik merupakan salah satu faktor yang sangat penting dalam perencanaan dan pengembangan pabrik. Penentuan lokasi pabrik sangat ditentukan oleh beberapa faktor penunjang yang sangat mempengaruhi proses dalam industri untuk didapatkan kelayakan distribusi dan biaya produksi yang minimal sehingga didapatkan keuntungan bagi kemajuan dan perkembangan pabrik tersebut.

Disamping pertimbangan teknis dan ekonomis diperlukan pula pertimbangan sosiologis, yaitu pertimbangan dalam mempelajari sifat dan sikap masyarakat di sekitar daerah yang dipilih sebagai lokasi pabrik, sehingga jika ada hambatan sosiologis yang timbul dari luar dapat diperhitungkan sebelumnya. Peta lokasi pabrik dapat dilihat pada gambar 4 .

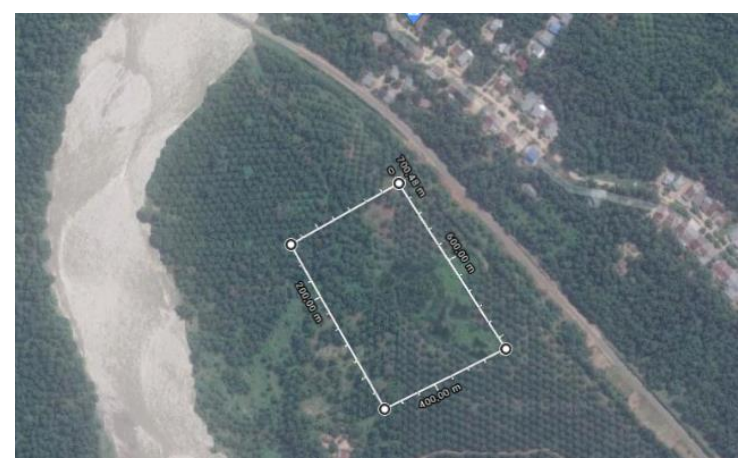

Gambar 4. Lokasi Pabrik (Google maps)

Berdasarkan pertimbangan diatas, maka pabrik bio-diesel ini direncanakan didirikan di Kecamatan Bandar, Kabupaten Simalungun, Sumatera Utara Alasan pemilihan daerah ini sebagai lokasi disebabkan oleh beberapa faktor sebagai berikut:

\section{a. Sumber Bahan Baku}

Bahan baku pembuatan Metil Metakrilat adalah PFAD. Ketersedian PFAD di Sumatera Utara tahun 2024 yaitu sebesar 1.189.692. PFAD yang dibutuhkan untuk menjalankan pabrik dengan kapasitas produksi 100.000 ton/tahun ini adalah 13,45\% dari ketersedian di Sumatera Utara yaitu 160.000 ton/tahun. Bahan baku PFAD tersebut diperoleh dari beberapa perusahaan di Sumatera Utara yang dapat menunjang ketersediaan bahan baku berupa PFAD ini Sehingga dilihat dari segi bahan baku, maka pemilihan lokasi di di Kecamatan Bandar, Kabupaten Simalungun, Sumatera Utara merupakan lokasi yang cukup startegis karena berada pada akses jalan raya, jembatan dan sungai yang dapat membantu distribusi dari segi darat dan sungai.

\section{b. Utilitas}

Untuk menjalankan proses produksi pabrik diperlukan sarana pendukung seperti pembangkit tenaga listrik dan penyediaan air. Air untuk keperluan pabrik, baik untuk proses maupun untuk keperluan sanitasi dan 
lainnya perlu diperhatikan. Untuk penggunaannya, air ini harus diolah terlebih dahulu agar memenuhi persyaratan terutama untuk keperluan proses dan steam. Sumber air diperoleh dari sungai yang berada di sekitar pabrik yakni Bah Bolon. Sedangkan untuk tenaga listrik diperoleh dari pembangkit listrik yang dibangun sendiri dan dibangkitkan oleh generator.

\section{Ekonomi}

Hasil dari analisa ekonomi dari Pra Rancangan ini adalah:

1. Total Capital Investment =

US \$ 226.224.209,2244

2. Selling Price

$$
\begin{aligned}
& =\text { US } \$ 256.246 .415,6398 \\
& =\text { US } \$ 159.184 .636,4250 \\
& =3 \text { Tahun } \\
& =27,8883 \% \\
& =20,49 \% \\
& =33,7298 \%
\end{aligned}
$$

\section{Tugas Khusus}

Destilasi merupakan suatu proses pemisahan dua atau lebih komponen zat yang memiliki perbedaan titik didih berdasarkan pada volatilitas. Secara sederhana destisi dilakukan dengan memanaskan/menguapkan zat cair lalu uap tersebut didinginkan kembali supaya jadi cair dengan bantuan kondensor. Destilasi digunakan untuk memurnikan zat cair, yang didasarkan atas perbedaan titik didih cairan. Prinsip dasar dari destilasi adalah perbedaan titik didih dari zat-zat cair dalam campuran zat cair tersebut sehingga zat (senyawa) yang memiliki titik didih terendah akan menguap lebih dahulu, kemudian apabila didinginkan akan mengembun dan menetes sebagai zat murni (destilat) (Cammack, 2006).

Proses destilasi menggunakan alat yang disebut denggan kolom destilasi. Pada industri pembutan biodiesel jenis destilasi yang sering digunakan yang destilasi vakum. Destilasi vakum merupakan destilasi yang memisahkan dua kompenen yang titik didihnya sangat tinggi, motode yang digunakan adalah dengan menurunkan tekanan permukaan lebih rendah dari $1 \mathrm{~atm}$, sehingga titik didihnya juga menjadi rendah, dalam prosesnya suhu yang digunakan untuk mendestilasinya tidak perlu terlalu tinggi. Beberapa bahan organik tidak dapat didestilasi secara memuaskan pada tekanan atmosfer, sebab akan mengalami penguraian atau dekomposisi sempurna sebelum titik didih nirmal tercapai. Dengan mengurangi tekanan eksternal 0,1-30 mmHg, titik didih dapat diturunkan dan destilasi dapat berlangsung tanpa mengakibatkan terjadinya dekomposisi. (Walangare, 2013). 


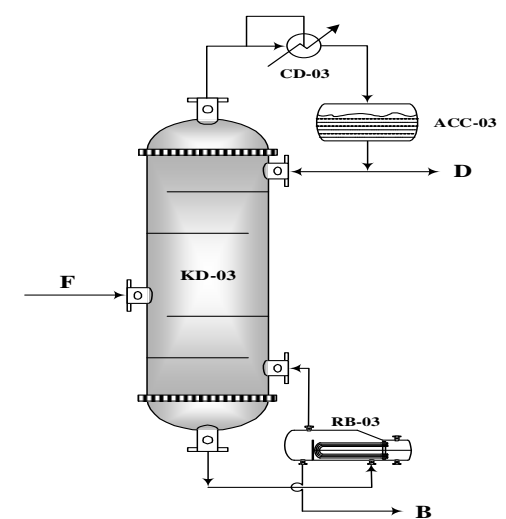

Gambar 5. Kolom Distilasi

\begin{tabular}{cll}
\hline \multicolumn{3}{c}{ IDENTIFIKASI } \\
\hline Nama Alat & Kolom Destilasi \\
Kode Alat & KD-03 \\
Jumlah & 1 unit \\
& Unt Untuk memisahkan \\
Fungsi & unsaponifiable \\
\hline \multicolumn{3}{c}{ DATA DESAIN } \\
\hline Bottom \\
Tekanan & 0,0002 atm & 0,0131 atm \\
Suhu & $231,475^{\circ} \mathrm{C}$ & $265,949^{\circ} \mathrm{C}$ \\
Hole Diameter & $5 \mathrm{~mm}$ & $5 \mathrm{~mm}$ \\
Panjang Weir & $1,1807 \mathrm{~m}$ & $1,1807 \mathrm{~m}$ \\
Tebal Pelat & $5 \mathrm{~mm}$ & $5 \mathrm{~mm}$ \\
Jumlah Hole & 1.090 holes & 1.090 holes \\
Diameter & $1,5135 \mathrm{~m}$ & $1,5135 \mathrm{~m}$ \\
Tinggi & $21,6 \mathrm{~m}$ & \\
Jumlah Stage & 72 & \multicolumn{2}{c}{ DATA MEKANIK } \\
\hline \multicolumn{3}{c}{ Carbon Steel } \\
\hline Bahan Konstruksi
\end{tabular}

\section{Daftar Pustaka}

[1]Cammack, R. 20016. Oxford Dictionary Of Biochemistry and Molecular Biology. Oxford University Press. New York. 720

[2] Walangare, dkk. 2013. Rancang bangun alat konversi air laut menjadi air minum dengan proses destilasi sederhana menggunakan pemanas elektrik. Yogyakarta : Pustaka Pelajar 